\title{
Structure-property relationship of recycled carbon fibres revealed by pyrolysis recycling process
}

\author{
Guozhan Jiang, Stephen J Pickering
}

\begin{abstract}
The structure-property relationship for recycled carbon fibres is investigated by characterisation of the structure changes induced by the pyrolysis recycling process. Two important factors influencing the properties of recycled carbon fibres are identified for various recycling processes: oxidative effect and thermal effect. The oxidative effect results in surface defects, and the surface defects causes a reduction in tensile strength and lateral crystallite size. The thermal effect of the recycling process results in an expansion in the distance between graphite layers and a decrease in surface oxygen concentration, which would lead to a drop in interfacial shear strength with epoxy resins. The tensile strength of recycled carbon fibres has a strong correlation with the intensity ratio of the $D$ and $G$ bands of the Raman spectra $\left(I_{D} / I_{G}\right)$. With an increase in $I_{D} / I_{G}$, the tensile strength of recycled carbon fibre decreases linearly.
\end{abstract}

\section{Key words}

Recycled carbon fibre; structure-property relationship; oxidation; pyrolysis

\section{Guozhan Jiang}

Division of Materials Mechanics and Structures, University of Nottingham, Nottingham NG7 2RD, United Kingdom

Email: Guozhan.jiang@wlv.ac.uk

Stephen J Pickering*

Division of Materials Mechanics and Structures, University of Nottingham, Nottingham NG7 2RD, United Kingdom

Email: Stephen.pickering@nottingham.ac.uk

Tel: +44 1159513785 


\section{Introduction}

Recycling carbon fibre from waste streams of carbon fibre reinforced plastics (CFRP) is important in sustainable utilisation of high value carbon fibres in manufacturing lightweight vehicles. In the last two decades, a great attempt has been made in the development of recycling process, characterisation and application of various recycled carbon fibres.

However, there still lacks a comprehensive understanding of structure-property relationship for the recycled fibres to underpin further optimisation of recycling processes and quality control of large-scale operations.

An insight into the structure-property relationship depends on the appraising of the three major recycling processes: thermo-oxidation, pyrolysis and solvolysis [1]. In the thermo-oxidation process, shredded CFRPs are fed into a fluidised bed reactor in which a quartz sand bed is fluidised using hot air at $500-600^{\circ} \mathrm{C}$. The thermoset polymer matrix is oxidized in the bed to gaseous products and the carbon fibre is released and carried away in the hot gas stream and then collected as products [2]. In the pyrolysis recycling process, CFRP materials are pyrolysed first in a reactor at $500-600^{\circ} \mathrm{C}$ in the absence of oxygen. The char left on the carbon fibre surface is subsequently oxidized using hot air to produce clean carbon fibres [3]. In the solvolysis recycling process, CFRP materials are processed in a reactor containing a suitable solvent such as supercritical water [4] and propanol [5] at high temperatures and/or pressures. The thermoset polymer matrix is decomposed in the solvent. Unlike pyrolysis in an inert gas, char formation is suppressed in a hot solvent due to the avoidance of secondary reactions of the decomposition products. In this process, carbon fibre can be recovered in one step without the need of an oxidation step, but the use of high pressure supercritical fluids leads to high costs in plant and equipment associated with process pressure. In our previous studies, we characterised carbon fibres recycled using a thermo-oxidative $[6,7]$ and a supercritical propanol process [5]. The Young's modulus of the recycled carbon fibres has no significant changes for the both recycling processes. For thermo-oxidative recycling, there is a $20-40 \%$ reduction in tensile strength and a slight reduction in surface oxygen. In contrast, there is little reduction in tensile strength, but a significant reduction in surface oxygen for the solvent recycling.

In the three major recycling processes, the key step to recycle carbon fibres from CFRP is to break down the thermoset matrix into small molecules to release the carbon fibres 
inside. Due to the chemical stability of the thermoset resins, thermal or thermo-oxidative decomposition pathway is responsible for all recycling processes. Therefore, the effects of recycling on fibre properties can be attributed to two factors: oxidative effect and thermal effect. In thermo-oxidation recycling, the two effects are working together, while in solvolysis recycling, only the thermal effect is present since the solvent does not take part in the reaction. According to the properties of the recycled carbon fibres from thermooxidation and solvolysis recycling processes, it can be inferred that thermal effect does not induce changes of mechanical properties but results in a reduction in surface oxygen. The reduction in tensile strength in the thermo-oxidation recycling may be attributed exclusively to oxidative effect.

It is desirable to understand whether these two effects on the properties of recycled carbon fibres are universal. The aim of the present work is to further understand the thermal and oxidative effects in order to establish a structure-property relationship for recycled carbon fibres. This will be achieved by investigating the properties of the recycled carbon fibres from pyrolysis recycling process. In pyrolysis recycling, the two effects are working at different stages. Investigating the properties of the recycled carbon fibres is expected to reveal the underlying mechanisms of how the two recycling effects work.

\section{Experimental}

\section{Materials}

Two batches of recycled carbon fibres (RCF1 and RCF2) were provided by ELG Carbon Fibre Ltd (UK), which were recycled by ELG using a pyrolysis process from the same source of cured epoxy/T800s prepregs. The difference between RCF1 and RCF2 was due to the quality variation from batch to batch. The prepregs were first pyrolysed at $500^{\circ} \mathrm{C}$ and then the char left on the carbon fibre surface was removed by oxidation in air. The recycled carbon fibres were in chopped form with a length of $12 \mathrm{~mm}$. Virgin T800s carbon fibre (vCF) extracted from the un-cured form of the same source of prepregs were used as a comparison. The extraction was carried out in a Soxhlet extractor by methyl ethyl ketone for 24 hours and then dichloromethane for another 24 hours [8-10]. After extraction, the fibre was placed in an oven at $80^{\circ} \mathrm{C}$ for later use.

\section{Characterisation}




\section{Scanning electron microscope (SEM)}

The morphology change of the virgin and the recycled carbon fibres was observed using a Philips XL30 scanning electron microscope. The specimens were fixed on an aluminium stub and then gold-sputtered. The longitudinal surface of the carbon fibres was observed with an accelerating voltage of $10 \mathrm{kV}$ under secondary electron mode.

\section{X-ray photoelectron spectroscopy (XPS)}

The XPS facility was a VG ESCALAB-5 Mark II spectrometer using Al Ka radiation ( $h v=$ $1486.6 \mathrm{eV})$. The $\mathrm{X}$-ray source was run at $10 \mathrm{kV}$ and $24 \mathrm{~mA}$. The carbon fibres were mounted on a standard aluminium stud by means of a double-sided adhesive tape. The analyser pass energy was $50 \mathrm{eV}$ for survey scans from 0 to $1200 \mathrm{eV}$, and $10 \mathrm{eV}$ for high resolution scans. All spectra were obtained at a take-off angle of $90^{\circ}$.

The spectra were processed using CasaXPS software. At first, the binding energy was corrected by referring to the graphitic C1s peak after setting its binding energy to $284.6 \mathrm{eV}$. The surface atomic percentages were calculated from the survey spectra according to the peak area and the sensitivity factor derived from Scofield Library. The amount of various oxygen functionalities were determined using the C1s high resolution spectra by curvefitting of six components: graphitic carbon, $\beta$-carbon (carbons adjacent to carbon atoms bonded to oxygen), $\mathrm{C}-\mathrm{OH}, \mathrm{C}=\mathrm{O}, \mathrm{COOH}$, and $\pi-\pi^{*}$ transition [11]. During curve-fitting, an asymmetric line shape was used for the graphitic peak, which was a Gaussian-Lorentzian product function (80\% Gaussian) with an exponential tail provided by the software $[12,13]$. A symmetric line shape was used for the other peaks, which was a Gaussian-Lorentzian product function (50\% Gaussian). The width of the graphitic carbon component was set 0.9$1.2 \mathrm{eV}$. The widths of the other peaks were not set restriction but the same width was set. The positions of $\beta$-carbon, $\mathrm{C}-\mathrm{OH}, \mathrm{C}=\mathrm{O}, \mathrm{COOH}$ and $\pi-\pi^{*}$ transition were $0.6,1.5,3.0,4.5$ and $6.9 \mathrm{eV}$ relative to graphitic carbon respectively, each with a variation of $\pm 0.1 \mathrm{eV}$.

The magnitude of the exponential tail to the graphitic carbon was obtained by an internal consistency [14], which requires that the amount of oxygen determined from the curve fitting is the same as that determined from the survey spectra [15], as shown in Eq.1.

$$
\mathrm{O} \%=A_{\mathrm{c}-\mathrm{OH}}+A_{\mathrm{C}=\mathrm{O}}+2 A_{\mathrm{COOH}}
$$


where $A$ represents the atomic percentage, the subscripts represent different oxygen functionalities, and $O \%$ represents the oxygen atomic percentage determined from the survey spectra.

\section{Surface energy measurement}

The surface energy of the carbon fibres was determined using a droplet height-droplet length method [16]. The probing liquids used were 1-bromonaphthalene, formamide and glycerol. The surface tensions and their polar and dispersion components of these liquids are listed in Table 1. Before measuring surface energy, the recycled carbon fibre was cleaned by ultra-sonication to remove any particles on the surface. A single fibre was stretched across a PTFE frame and then fixed to the frame using cellotape. Liquid droplets were formed on the fibre by soaking into a probing liquid and then drawing out slowly. The droplet length I and height $h$ were measured using an optical microscope. The fibre diameter $D$ was measured using a laser scan micrometer (Mitutoyo Model LSM 501S).

The contact angle $(\vartheta)$ was obtained by analysing the profile of the droplet. A profile of a droplet together with coordinate system is shown in Fig.1. The reduced length $Y(=2 / / D)$ and reduced height $H(=2 h / D)$ obey Eq.2 [16]. Eq. 2 was solved using a shot-and-check method, in which the correct value of the contact angle was obtained by making the difference between $Y(L)$ and 1 less than a small value of $10^{-3}$ [17]. For each probing liquid, 20 droplets were measured and analysed and the contact angle reported was the average of the 20 measurements.

$$
\begin{aligned}
& Y^{\prime \prime}+2 \frac{H-\cos \theta}{H^{2}-1}\left(1+Y^{\prime 2}\right)^{3 / 2}-\frac{1+Y^{\prime 2}}{Y}=0 \\
& \mathrm{Y}(0)=1, \mathrm{Y}(\mathrm{L})=1, \mathrm{Y}^{\prime}(0)=\tan \theta
\end{aligned}
$$

The dispersion component $\gamma^{d}$ and polar component $\gamma^{p}$ and total surface energy $\left(\gamma^{s}=\gamma^{d}\right.$ $\left.+\gamma^{p}\right)$ of the carbon fibres was calculated using Eq.3 [18].

$$
\gamma_{L}(1+\cos \theta) / 2 \sqrt{\gamma_{L}^{d}}=\sqrt{\gamma_{s}^{p}}\left(\sqrt{\gamma_{L}^{P}} / \sqrt{\gamma_{L}^{d}}\right)+\sqrt{\gamma_{s}^{d}}
$$

where $\gamma$ represents surface tension or surface energy, subscript $L$ represents liquid, $S$ represents solid (carbon fibre), superscript $p$ represents polar component and $d$ represents non-polar (dispersion) component of surface energy. 


\section{X-ray diffraction (XRD)}

Wide angle X-Ray diffraction were obtained using a Siemens D500 diffractometer and CuK $\alpha_{1}$ radiation with a graphite monochromator. Silicon powder was used as an internal standard to correct the peak position and width. The amount of silicon was added to obtain a comparable peak height of silicon (111) peak with the (002) peak of the samples. The carbon fibre was ground using mortar and pestle into fine powders. The diffraction was performed at ambient temperature. Data were collected in the $2 \theta$ range of $14-60^{\circ}$ with a step of $0.0025 / \mathrm{s}$ and a scan time of $3 \mathrm{~s}$.

Before analysing the XRD diffraction trace, the $K \alpha_{2}$ component was removed. The trace was smoothed using Savitsky-Golay method, and then a spline background was subtracted. The (002) and (100) profile were fitted using Pearson VII model. Bragg equation (Eq.4) and Scherrer's formula (Eq.5) were used to calculate the interlayer spacing $\left(d_{002}\right)$, the mean defect-free stack height $\left(L_{c}\right)$ and the mean diameter of lateral crystallite size $\left(L_{a}\right)$.

$$
\begin{aligned}
& d_{002}=\lambda / 2 \sin \theta \\
& L=K \lambda / \beta \cos \theta
\end{aligned}
$$

where $\lambda$ is the wavelength of $\mathrm{CuK \alpha _{1 }}$ radiation, which is $0.15405 \mathrm{~nm}, \vartheta$ is the Bragg diffraction angle, $B$ is the full width at half maximum intensity (FWHM), $K$ is the Scherrer shape factor, which is 0.89 for (002) peak and 1.84 for (100) peak [19]. The displacement of the specimen from the diffractometer axis was corrected using Eq.6 [19].

$$
\Delta d / d=-D \cos ^{2} \theta / R \sin \theta
$$

where $D$ is the specimen displacement parallel to the reflecting-plane normal and $R$ is the diffractometer radius. The value of $D / R$ for $d_{002}$ of graphitic crystallites was calculated using the standard values of $\mathrm{Si}(111)$ position and spacing.

\section{Raman spectroscopy}

Raman spectra of the carbon fibres were obtained using a Horiba LabRAM HR spectrometer at room temperature. He-Ne laser with $532 \mathrm{~nm}$ wavelength was used as an illumination source. The Rayleigh scattering was removed using a notch filter and the backscattered Raman light was dispersed by a 600 lines/mm optical grating. The incident laser beam was focused on the fibre through a 50 x objective lens and a $300 \mu \mathrm{m}$ confocal hole. $\mathrm{A}$ 
Synapse ${ }^{\circledR}$ CCD (charge-coupled device) detector was used to collect the Raman spectra. For each spectrum, six scans were collected and co-added in the instrument control computer. Each scan had an exposure time of 5 seconds. The Raman spectra were curve-fitted to a Voigt function using a non-linear least-squares routine [20, 21].

\section{Single fibre tensile testing}

The tensile properties of the carbon fibres were measured according to BS ISO 11566. The gauge length used was $6 \mathrm{~mm}$ for comparison with our previous studies. Twenty-five specimens were tested for each type of fibre. The tensile testing was performed on a Hunsfield testing frame with a $5 \mathrm{~N}$ load cell and a crosshead speed of $1 \mathrm{~mm} / \mathrm{min}$. The reported tensile strength was the mean of the Weibull distribution of the 25 measurements due to its statistical nature, and the reported modulus was the average of the 25 measurements.

\section{Single fibre pull-out testing}

The epoxy resin and polypropylene used for single fibre pull-out test was from Cytec (UK) with a brand name of EF6305 and Sigma-Aldrich (UK) respectively. A single filament of the carbon fibres was stretched across a paper window and bonded firmly to both the ends of the window using Aradite ${ }^{\circledR}$ glue. The micro-ball was cast on the fibre using a $\phi 90 \mathrm{~mm}$ copper filament attached to the tip of a temperature adjustable soldering iron. The end of the heated copper wire was allowed to contact the resin to attach a tiny drop of the melted resin. A micro-ball was formed by allowing the tiny drop of resin to touch the fibre. The preparation was under a microscope with a platform that can move in three dimensions. The epoxy resin micro-balls were cured at $120^{\circ} \mathrm{C}$ for 1 hour in an oven, and the PP ball was cooled down at room temperature.

Before the pull-out testing, the diameter of the fibre was measured using a Mitutoyo Laser scan micrometer, and the length of the microball was measured using an optical microscope. The pull-out testing was conducted on a Hounsfield tensile testing machine with a micro-vise as described elsewhere $[5,22]$. Thirty test specimens were prepared for each type of fibre. The speed of the tensile testing was $1 \mathrm{~mm} / \mathrm{min}$. The interfacial shear strength was calculated using Eq. 7.

$$
\tau=F_{\max } / \pi D l
$$


where $I$ is the length of the micro-ball, $D$ is the diameter of the carbon fibre and $F_{\max }$ is the maximum force for pulling-out the fibre out of the ball.

\section{Results and discussion}

\section{Surface properties}

The surface properties of the recycled carbon fibres were examined using SEM, XPS and surface energy measurement. Typical SEM images of the carbon fibres are shown in Fig.2. Compared with the virgin fibre, the recycled fibres also have a clean smooth surface, although some particles are present on the RCF2 fibres. However, defects were not discernible under SEM.

Fig. 3 shows the XPS survey spectra and the superimposed C1s high resolution spectra of the carbon fibres. The oxygen/carbon atomic ratio $(\mathrm{O} / \mathrm{C})$ and the curve-fitting results are listed in Table 1. The XPS survey spectra show three peaks assigned to C1s (285 eV), O1s (531 eV) and N1s (402 eV). After recycling, the intensity of the O/C are remarkably reduced from 0.258 to 0.189 (RCF1) and 0.150 (RCF2), and the C1s spectra of the recycled carbon fibres have become narrower. Narrower $\mathrm{C} 1 \mathrm{~s}$ indicates a reduction in $\beta$ carbon component on the surface of the recycled carbon fibres [23]. $\beta$ carbon is the carbon adjacent to the carbon with oxygen functionalities ( $\alpha$-carbon). Reduction in $\beta$ carbon suggests that some oxygen functionalities on the $\alpha$-carbon have been removed, which is confirmed from the curve-fitting results listed in Table 2.

Early work by Zielke et al [24] suggests that oxygen functionalities on carbon fibre surface can be removed in the form of $\mathrm{CO}$ and $\mathrm{CO}_{2}$ by heating at high temperatures in an inert atmosphere or in vacuum. The pyrolysis recycling was conducted at $500^{\circ} \mathrm{C}$ in an inert gas and then hot air was employed to remove the residual char on the fibre surface. Hence, the surface oxygen on the surface of the recycled carbon fibres should be the combined result of the two steps. In pyrolysis step, most of the original surface oxygen functionalities could be removed. In the subsequent oxidation step, new oxygen functionalities could be generated. The reduction in $\mathrm{O} / \mathrm{C}$ of the recycled carbon fibres implies that the amount of the newly generated oxygen functionalities is less than that of the original ones. The extent of reduction of RCF2 could be a consequence of a less severe oxidation step. The small char particles on the surface shown in Fig. 2 may be a piece of evidence of the less oxidation. 
Table 3 lists the contact angles of the various probing liquids on the carbon fibres and the surface energies of the carbon fibres calculated from the contact angle data using Eq. 3. It can be seen from Table 2 that the surface energies and their components of the recycled carbon fibres are comparable to that of the virgin fibre. It is expected that the recycled carbon fibres has a lower surface energy since their surface oxygen concentrations are lower from the XPS measurement $[25,26]$. The similar surface energies are most likely caused by a higher surface area of the recycled carbon fibres according to Wenzel's theory $[27,28]$, which relates surface area to contact angle (Eq.8).

$$
\cos \theta^{\prime}=\delta \cos \theta
$$

where $\theta$ is the intrinsic contact angle, $\vartheta^{\prime}$ is the observed contact angle at a rough surface, and $\delta$ is the ratio of actual surface area to the geometry surface area. It can be seen from Eq.8 that the higher surface energy for the recycled carbon fibres indicates a higher $\delta$ value. The geometric surface area of the carbon fibres are similar $\left(=1 / 4 \pi D^{2}\right)$ since the diameter $D$ has little change after recycling. Higher $\delta$ values imply that the recycled carbon fibres had higher actual surface areas than the virgin carbon fibre, which suggests the existence of surface defects resulted from recycling.

\section{Structural properties}

The changes in crystallite structure of the recycled carbon fibres were examined using XRD and Raman spectroscopy. Fig. 4 shows the X-ray diffraction traces for the carbon fibres, and the crystallite parameters of the carbon fibres calculated based on the XRD measurement are present in Table 4. Excluding the silicon peaks and the noise peak at $\sim 38^{\circ}$ for RCF2 pattern, the carbon fibres show only two peaks with intensity maxima at around $25^{\circ}$ and $43^{\circ}$, which are attributed respectively to (002) reflection and (100) reflection of the stacking of the graphitic plates. After recycling, the interlayer distance $d_{002}$ increased from $0.345 \mathrm{~nm}$ to $0.347-0.349 \mathrm{~nm}$, and the stack heights $L_{c}$ increased from $1.9 \mathrm{~nm}$ to around 2.0 $\mathrm{nm}$. Other researchers have shown that $d_{002}$ increases when graphitized carbon materials is heat treated in nitrogen [29] and in vacuum [30], but remains unchanged by plasma or anodic oxidation at room temperature $[31,32]$. The increase in $d_{002}$ and $L_{c}$ after recycling can thus be attributed to the thermal effect of the recycling process. 
The lateral crystallite size $L_{a}$ decreased from $6 \mathrm{~nm}$ to around $5 \mathrm{~nm}$ after recycling. The reduction in $L_{\mathrm{a}}$ can be further confirmed by the Roman spectra of the carbon fibres. A single crystal of graphite exhibits only one first order Raman band at $1580 \mathrm{~cm}^{-1}$ ( $\mathrm{G}$ band). When the size of the crystallite decreases, i.e. the percentage of the edges of graphite planes is increased, a Raman band appears at $1360 \mathrm{~cm}^{-1}$ (D band) $[33,34]$. The ratio of the intensity of the $D$ and $G$ bands can be used to measure the graphitic plane size $L_{a}$ in a thin surface layer of any carbon sample [33]. The higher the ratio, the smaller the $L_{a}$ will be. In some carbon materials, a shoulder to the $G$ band is visible at about $1620 \mathrm{~cm}^{-1}\left(D^{\prime}\right.$ band), and a broad band is visible at the minimum of the $G$ and $D$ bands at around $1500 \mathrm{~cm}^{-1}\left(D^{\prime \prime}\right.$ band) [35-37]. A band may also appear at around $1200 \mathrm{~cm}^{-1}$ (I band) [38]. The origins of $D^{\prime}, \mathrm{D}^{\prime \prime}$ and I bands may be associated with the occurrence of certain functionalities or purely structural factors [36].

Fig. 5 shows the first order Raman spectra for the carbon fibres. All the spectra exhibit two broad Raman bands at about $1350 \mathrm{~cm}^{-1}$ and $1580 \mathrm{~cm}^{-1}$ corresponding to the $\mathrm{D}$ and $\mathrm{G}$ bands respectively. $D^{\prime \prime}$ band was discernible at about $1500 \mathrm{~cm}^{-1}$ using the secondary derivative of the spectra, but $D^{\prime}$ and I bands were not discernible. Hence, the spectra were fitted using three bands, at around $1360 \mathrm{~cm}^{-1}, 1500 \mathrm{~cm}^{-1}$ and $1580 \mathrm{~cm}^{-1}$ respectively. The curve fitting results are also given in Table 4 . The ratios of the integrated intensities of $D$ and $\mathrm{G}$ bands $\left(I_{\mathrm{D}} / \mathrm{I}_{\mathrm{G}}\right)$ were larger for the recycled carbon fibres, indicating that the lateral crystallite size $L_{a}$ of the recycled fibres had become smaller. Furthermore, it can be noticed that the positions of both $\mathrm{G}$ band and $\mathrm{D}$ band were shifted towards higher wave-number and the $\mathrm{D}$ bands became broader after recycling, which can also be evidence of a reduction in $L_{a}$ [36]. The penetration depth of the laser beam of Raman into the carbon fibre is only of the order of $60 \mathrm{~nm}$ [39-42], and so the Raman spectra only contains information from the fibre surface regions. It can therefore be inferred that the reduction in $L_{a}$ is due to the existence of surface defects indicated in the surface energy measurement, because the surface defects can disrupt the continuity of crystallites of surface layers.

\section{Mechanical and interfacial properties}

Table 5 lists the tensile testing results of the fibres. The Young's modulus of the recycled fibres was 368.7 and 331.2 GPa respectively, while the modulus of the virgin carbon fibre is $355.7 \mathrm{GPa}$. Within the experimental error, the Young's modulus of the fibres 
has no changes after recycling, which is similar to our previous findings for thermo-oxidative and supercritical propanol recycling processes [7]. The tensile strengths of the recycled fibres are $10-15 \%$ smaller than that of the virgin fibre. The extent of reduction is between those recycled using thermo-oxidative and supercritical propanol processes [7].

Young's moudulus of carbon fibres depends mainly on the preferred orientation of the graphite layers planes, as shown in Eq. 9 derived by Northolt et al. [43].

$$
1 / E=1 / e_{1}+\left\langle\cos ^{2} \varphi\right\rangle / g
$$

where $E$ is the Young's modulus, $e_{1}$ is the elastic modulus of graphite crystals (approximately $1030 \mathrm{GPa}), g$ is the shear modulus of the graphite crystal, $\phi$ is the angle between graphitic plane and fibre axis, and $\left\langle\cos ^{2} \phi\right\rangle$ represents the averaged preferred orientation of crystallites. According to Eq.9, the averaged preferred orientation of crystallites of the recycled carbon fibres should have no significant change relative to that of the virgin fibre, which leads to no significant changes in the Young's modulus of the recycled carbon fibres.

A major difference between the three recycling processes is the duration of oxidation with a descending order: thermo-oxidative $(10 \mathrm{~min})>$ pyrolysis $(5 \mathrm{~min})>$ supercritical propanol $(0 \mathrm{~min})$. Since heat treatment in an inert atmosphere does not alter the strength [30], the reduction in strength can be attributed to the oxidative effect of the recycling.

The strength of carbon fibre is controlled by the distribution of defects [44, 45]. Hence, a lower tensile strength corresponds to a larger population of defects. In the previous sections, it has been shown that the recycling process generated surface defects due to the oxidation effect and the defects resulted in a decrease in $L_{\mathrm{a}}$. The larger the reduction in $L_{\mathrm{a}}$, the larger the extent of reduction in tensile strength will be. It can thus be inferred that the strength should have a relationship with the crystallite size $L_{\mathrm{a}}$. To observe the trend, the strength of the fibres was plotted in Fig. 6 against $L_{a}$ measured using XRD and the Raman band intensity ratio $I_{D} / I_{G}$ (an indication of $L_{\mathrm{a}}$ ). It can be seen from Fig. 6 that the tensile strength had a stronger correlation with $I_{D} / I_{G}$ than with $L_{a}$. The stronger correlation between the tensile strength and the $I_{D} / I_{G}$ indicates that the defects are concentrated on surface layer since sampling depth for Raman is much closer to the surface than that of XRD. 
The interfacial shear strength of the fibres with epoxy and polypropylene are also shown in Table 4. It is generally believed that good adhesion between carbon fibre and polymer matrix depends on surface chemical interactions and/or mechanical locking due to surface roughness [46-48]. The interfacial shear strength of the recycled carbon fibres with the epoxy resin was about $20 \mathrm{MPa}$ lower than that for virgin fibre, while the interfacial shear strength with polypropylene is similar for all the fibres. Since polypropylene is a non-polar polymer, its adhesion with carbon fibre depends mainly on mechanical locking effect. The comparable values of interfacial shear strength with polypropylene indicate that the mechanical locking effect of the carbon fibre did not change after recycling. Therefore, the reduction in interfacial shear strength with the epoxy resin can be attributed to the reduction in surface oxygen functionalities.

\section{Conclusions}

In this work, carbon fibres recycled using pyrolysis process were characterised using various methods to develop an understanding of the changes in surface and microstructure From the surface, micro-structure and mechanical properties of the recycled carbon fibres, a clear picture of the structure-property relationship for recycled carbon fibre has been obtained.

After pyrolysis recycling, the surface oxygen atomic concentration has a reduction of $2.6-42 \%$. However, the surface energy has little reduction due to the surface defects induced by the recycling process. The reduction in surface oxygen results in an approximate $24 \%$ reduction of interfacial shear strength with epoxy resin.

The pyrolysis recycling results in an expansion of the layer distance and a reduction in lateral size of the graphitic crystallites. The tensile strength of the recycled carbon fibre has an approximate reduction of $2-16 \%$, which has a stronger correlation with the Raman spectra band ratio $I_{D} / I_{G}$, indicating that the defects resulted from the recycling are concentrated on the surface of the recycled carbon fibres.

By comparison with the properties and structures of the carbon fibres recycled using thermos-oxidation and solvolysis [5-7], the following generic conclusions may be drawn. Recycling involves both thermal and oxidative effects. The thermal effect results in an expansion of graphitic layer distance, and a remarkable reduction in surface oxygen. The 
oxidative effect results in surface defects and a reduction in lateral crystallite size. The Raman spectra band $I_{D} / I_{G}$ may be exploited to correlate with the strength of recycled carbon fibres.

\section{Acknowledgements}

This work was financially supported by EPSRC through the Nottingham Innovative Manufacturing Research Centre (NIMRC). We also acknowledge the supply of recycled carbon fibre by ELG Carbon Fibre Ltd (UK).

\section{References}

[1] Pickering S] (2006) Recycling technologies for thermoset composite materials current status. Composites: Part A 37: 1206-1215.

[2] Jiang G, Wong WH, Pickering SJ, Rudd CD, Walker GS (2005) Proceedings of 7th World Congress for Chemical Engineering, Glasgow, UK

[3] Davidson J, Price R (2009) Recycling carbon fibres, EP2152487

[4] Knight CC, Zeng C, Zhang C, Wang B (2011) International SAMPE Technical Conference, Long Beach, CA

[5] Jiang G, Pickering SJ (2009) Characterisation of carbon fibre recycled using supercritical n-propanol. Compos Sci Technol 69: 192-198.

[6] Jiang G, Pickering SJ, Wong KH, Rudd CD, Walker GS (2008) Surface characterisation of carbon fibre recycled using high temperature fluidised bed. Appl Surf Sci 254: 2588-2593.

[7] Yip HLH, Pickering SJ, Rudd CD (2002) Characterisation of carbon fibers recycled from scrap composites using fluidised bed process. Plast Rub Compos 31: 278282.

[8] Santiago F, Mansour AN, Lee RN (1987) XPS study of sizing removal from carbon fibers. Surf Interface Anal 10: 17-22.

[9] Weng LT, Poleunis C, Bertrand P, et al. (1995) Sizing removal and functionalization of the carbon fibre surface studied by combined TOF SIMS and XPS. J Adhes Sci Technol 9: 859-871.

[10] Desimoni E, Casella GI, Morone A, Salvi AM (1990) XPS determination of oxygencontaining functional groups on carbon-fibre surfaces and the cleaning of these surfaces. Surf Interface Anal 15: 627-634.

[11] Sherwood PMA (1996) Surface analysis of carbon and carbon fibers for composites. J Electron Spectrosc 81: 319-342.

[12] Viswanathan H, Rooke MA, Sherwood PMA (1997) X-ray photoelectron spectroscopic studies of carbon-fibre surfaces. 21. Comparison of carbon fibres electrochemically oxidized in acid using achromatic and monochromatic XPS. Surf Interface Anal 25: 409-417.

[13] Xie Y, Sherwood PMA (1990) X-ray photoelectron spectroscopic studies of carbon fibre surfaces. 11. Differences in the surface chemistry and bulk structure of different carbon fibres based on poly (acrylonitrile) and pitch and comparison with various graphite samples. Chem Mater 2: 293-299.

[14] Desaeger M, Reis MJ, Botelho do Rego AM, Lopes da Silva JD, Verpoest I (1996) Surface characterisation of poly (acrylonitrile) based intermediate modulus carbon fibres. J Mater Sci 31: 6305-6315. 
[15] Yumitori S (2000) Correlation of C1s chemical state intensities with the O1s intensity in the XPS analysis of anodically oxidized glass-like carbon samples. J Mater Sci 35: 139-146.

[16] Yamaki J, Katayama Y (1975) New methods of determining contact angle between monofilament and liquid. J Appl Polym Sci 19: 2897-2909.

[17] Dumitrascu N, Borcia C (2006) Determining the contact angle between liquids and cylindrical surfaces. J Colloid Interf Sci 294: 418-422.

[18] van Oss CJ (1994) Interfacial Forces in Aqueous Media. Marcel Dekker, New York

[19] Cullity BD (1978) Elements of X-Ray Diffraction. Addison-Wesley, Reading

[20] Yamauchi S, Kurimoto Y (2003) Raman spectroscopic study on pyrolyzed wood and bark of Japanese cedar: temperature dependence of Raman parameters. J Wood Scie 49: 235-240.

[21] Zickler GA, Smarsly B, Gierlinger N, Peterlik H, Paris O (2006) A reconsideration of the relationship between the crystallite size La of carbons determined by X-ray diffraction and Raman spectroscopy. Carbon 44: 3239-3246.

[22] Jiang G, Pickering SJ (2012) Recycled carbon fibres: contact angles and interfacial bonding with thermoset resins. Mater Sci Forum 714: 255-261.

[23] Wang Y, Viswanathan H, Audi AA, Sherwood PMA (2000) X-ray photoelectron spectroscopic studies of carbon fiber surfaces. 22. Comparison between surface treatment of untreated and previously surface-treated fibers. Chem Mater 12: 1100-1107.

[24] Zielke U, Huttinger KJ, Hoffman WP (1996) Surface-oxidized carbon fibers: I. Surface structure and chemistry. Carbon 34: 983-998.

[25] Bradley RH, Ling X, Sutherland I (1993) An investigation of carbon fibre surface chemistry and reactivity based on XPS and surface free energy. Carbon 31: 11151120.

[26] Vickers PE, Watts JF, Perruchot C, Chehimi MM (2000) The surface chemistry and acid-base properties of a PAN-based carbon fibre. Carbon 38: 675-689.

[27] Wenzel RT (1936) Resistance of solid surfaces to wetting by water. Ind Eng Chem 28: $988-994$.

[28] Wenzel RT (1949) Surface roughness and contact angle. J Phys Colloid Chem 53: 1466-1467.

[29] Walker PL, McKinstry HA, Wright CC (1953) X-ray diffraction studies of a graphitized carbon: changes in interlayer spacing and binding energy with temperature. Ind Eng Chem 45: 1711-1715.

[30] Wang S, Chen Z, Ma W, Ma Q (2006) Influence of heat treatment on physicalchemical properties of PAN-based carbon fiber. Ceram Int 32: 291-295.

[31] Liu X, Yang C, Lu Y (2012) Contrastive study of anodic oxidation on carbon fibers and graphite fibers. Appl Surf Sci 258: 4268-4275.

[32] Guo Y, Liu J, Liang J (2005) Surface state of carbon fibers modified by electrochemical oxidation. J Mater Sci Technol 21: 371-375.

[33] Tuinstra F, Koenig JI (1970) Raman spectra of graphite. J Chem Phys 53: 11261130.

[34] Robertson J (1986) Amorphous carbon. Adv Phys 35: 317-374.

[35] Jawhari T, Roid A, Casado J (1995) Raman spectroscopic characterisatio of some commercialy available carbon black materials. Carbon 33: 1561-1565.

[36] Cuesta A, Dhamelincourt P, Laureyns J, Martinez-Alonso A, Tascon JMD (1994) Raman microprobe studies on carbon materials. Carbon 32: 1523-1532.

[37] Katagiri G, Ishida H, Ishitani A (1988) Raman spectra of graphite edge planes. Carbon 26: 565-571.

[38] Knight DS, White WB (1989) Characterization of diamond films by raman spectroscopy. J Mater Res 4: 385-393.

[39] Huang Y, Young RJ (1995) Effect of fibre microstructure upon the modulus of PAN- and pitch-based carbon fibres. Carbon 33: 97-107.

[40] Galiotis C, Batchelder DN (1988) Strain dependences of the first- and secondorder Raman spectra of carbon fibres. J Mater Sci Lett 7: 545-547. 
[41] Greenaway DL, Harbeke G, Bassani F, Tosatti E (1969) Anisotropy of the optical constants and the band structure of graphite. Phys Rev 178: 1340-1349.

[42] Sakata H, Dresselhaus G, Dresselhaus MS, Endo M (1988) Effect of uniaxial stress on the Raman spectra of graphite fibers. J Appl Phys 63: 2769-2772.

[43] Northolt MG, Veldhuizen LH, Jansen H (1991) Tensile deformation of carbon fibres and the relationship with the modulus for shear between the basal planes. Carbon 29: 1267-1279.

[44] Reynolds WN (1972) Structure and physical properties of carbon fibre. Chem Phys Carbon: 1-67.

[45] Reynolds WN, Moreton R (1980) Some factors affecting the strengths of carbon fibres. Phil. Trans. R. Soc. Lond. A294: 451-461.

[46] Fitzer E, Geigl K-H, Huttner W, Weiss R (1980) Chemical interactions between the carbon fibre surface and epoxy resins. Carbon 18: 389-393.

[47] Fitzer E, Weiss R (1987) Effect of surface treatment and sizing of C-fibres on the mechanical properties of CFR thermosetting and thermoplastic polymers. Carbon 25: 455-467.

[48] Horie K, Murai H, Mita I (1976) Bonding of epoxy resin to graphite fibres. Fibre Sci Technol 9: 253-264. 


\section{List of Figures}

Fig.1. A schematic diagram for a liquid droplet on a single fibre. / is the length of the droplet, $h$ is the height of the droplet, $r$ is the radius of the fibre, and $\vartheta$ is the contact angle of a probing liquid with the fibre. $X$ and $Y$ are reduced coordinate $(X=x / r, Y=y / r)$.

Fig.2. SEM images of carbon fibres recycled using the pyrolysis process. (a) virgin T800s; (b) RCF1; (c) RCF2.

Fig. 3. XPS survey spectra and C1s high resolution spectra of virgin and recycled T800s carbon fibres.

Fig. 4. X-ray diffraction patterns of virgin and recycled T800S carbon fibres.

Fig. 5. Raman spectra of the virgin and recycled T800s carbon fibres.

Fig. 6. Tensile strength of the carbon fibres versus the lateral crystallite size $\left(L_{a}\right)$ measured using XRD and the intensity ratio of the Raman $D$ and $G$ bands $\left(I_{D} / I_{G}\right)$.

\section{List of Tables}

Table 1. Surface tensions $\left(\gamma^{\mathrm{s}}\right)$ and their dispersion $\left(\gamma^{\mathrm{d}}\right)$ and polar $\left(\gamma^{p}\right)$ components of the three probing liquids used for measurement of contact angles with the carbon fibres.

Table 2. Oxygen functionalities (atomic \%) and oxygen/carbon ratio on the surface of virgin and recycled T800s carbon fibres determined using XPS. The numbers in the brackets are the standard deviation from the fitting routine.

Table 3. Contact angles of the three probing liquids on the virgin and recycled T800s carbon fibres and the surface energies of the carbon fibres calculated based on the contact angles. The numbers in the brackets are the standard deviation of the measurements.

Table 4. Microstructure parameters of the virgin and recycled T800s carbon fibres measured using XRD and Raman spectrometer.

Table 5. Tensile properties and interfacial shear strength (IFSS) of the virgin and recycled T800s carbon fibres with epoxy resin EF6305 and polypropylene. The number in the bracket is the standard deviation of the measurements. 


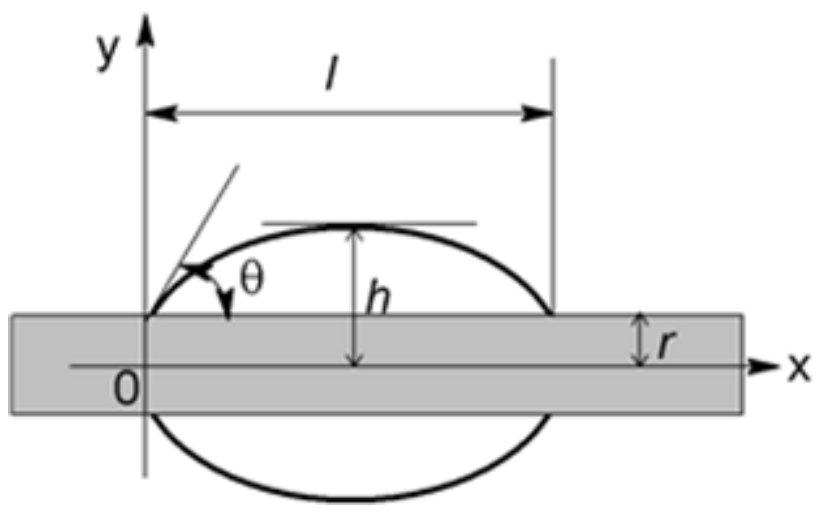

Figure 1
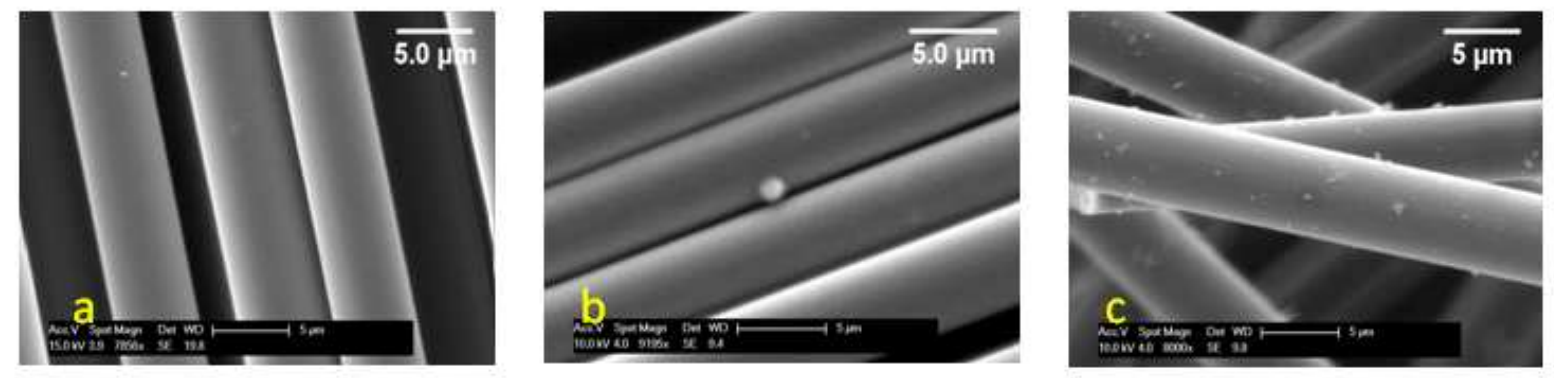

Figure 2 


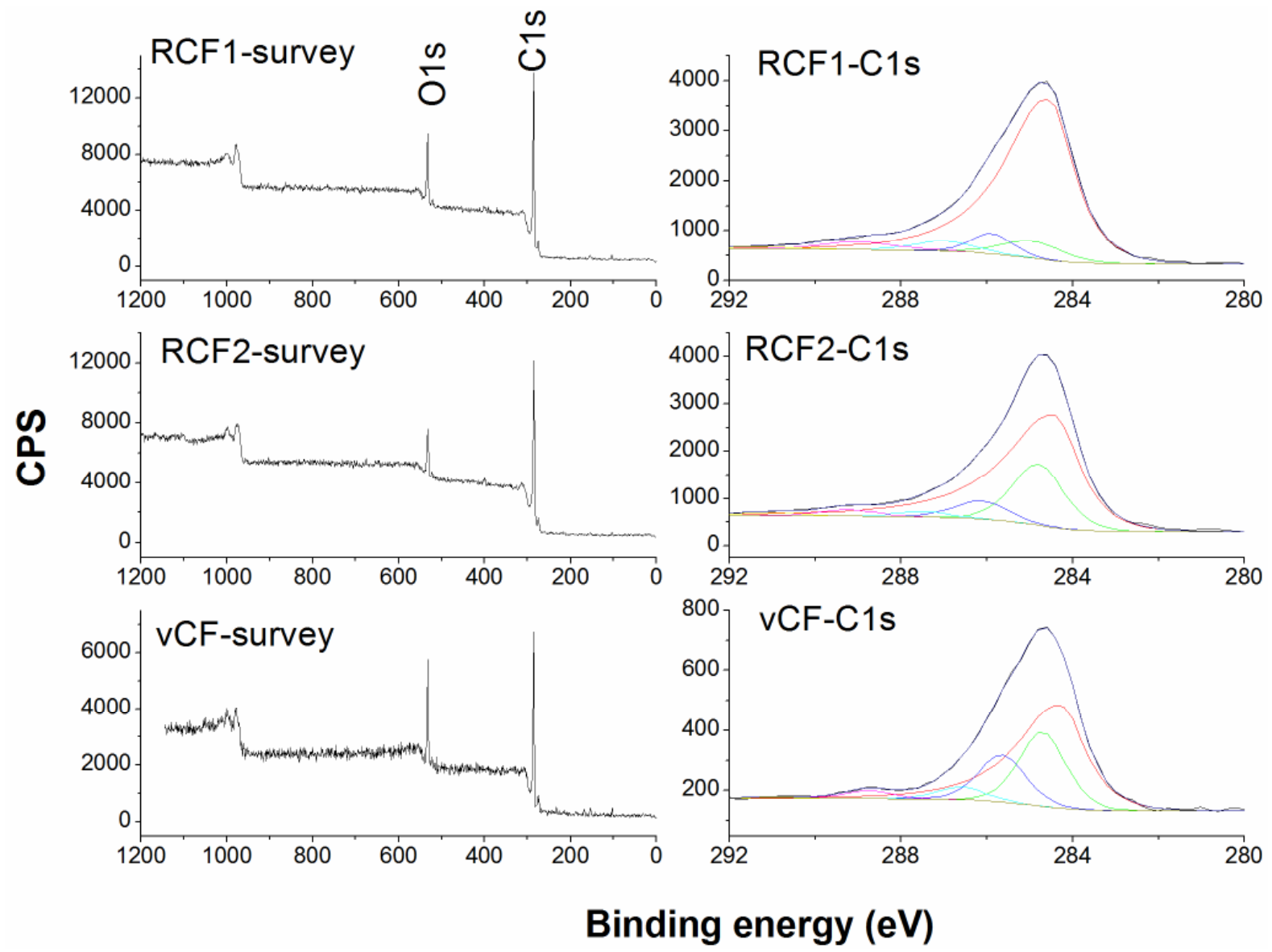

Figure 3

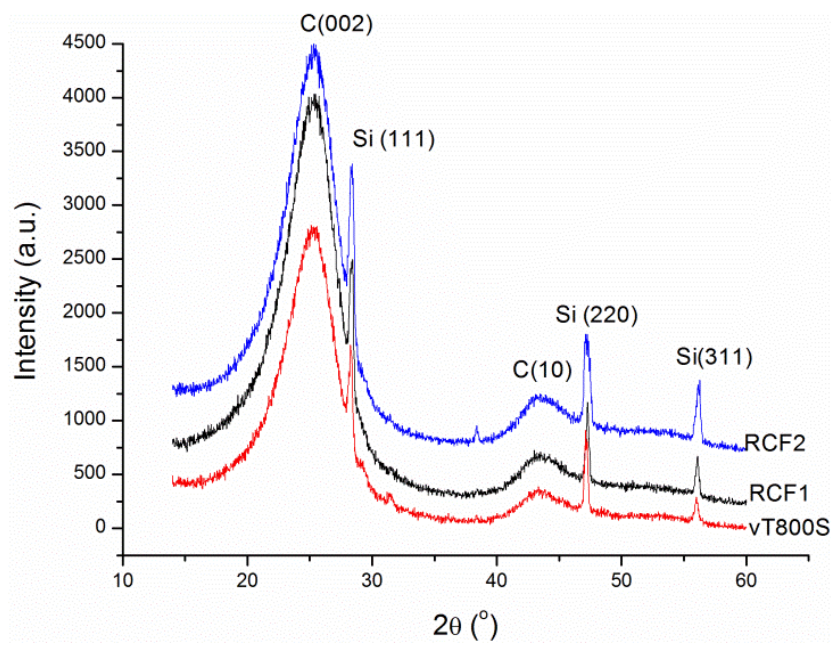

Figure 4 


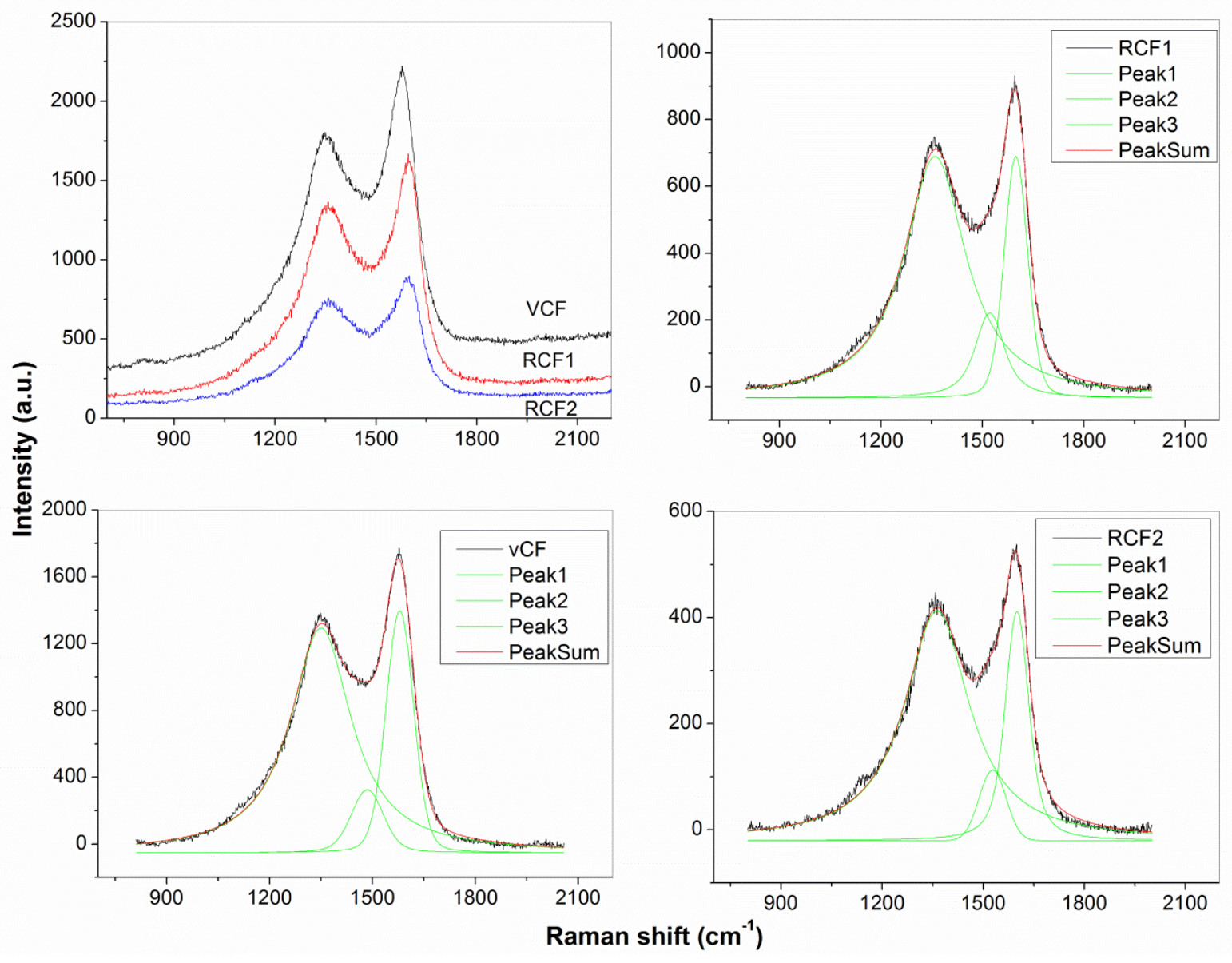

Figure 5

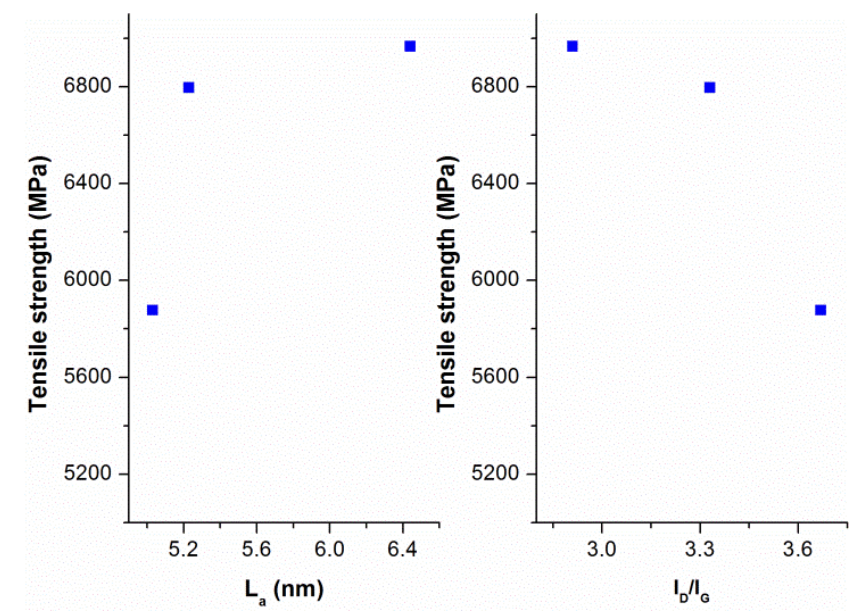

Figure 6 
Table 1. Surface tensions $\left(\gamma^{\mathrm{s}}\right)$ and their dispersion $\left(\gamma^{\mathrm{d}}\right)$ and polar $\left(\gamma^{\mathfrak{p}}\right)$ components of the three probing liquids used for measurement of contact angles with the carbon fibres.

\begin{tabular}{llll}
\hline Contact medium & $\gamma^{\mathrm{d}}(\mathrm{mN} / \mathrm{m})$ & $\gamma^{\mathrm{p}}(\mathrm{mN} / \mathrm{m})$ & $\gamma^{\mathrm{s}}(\mathrm{mN} / \mathrm{m})$ \\
\hline Formamide & 58.3 & 32.3 & 26.0 \\
1-Bromonaphthalene & 44.6 & 44.6 & 0 \\
Glycerol & 63.4 & 37.5 & 25.9 \\
\hline
\end{tabular}

Table 2. Oxygen functionalities (atomic \%) and oxygen/carbon ratio on the surface of virgin and recycled T800s carbon fibres determined using XPS. The numbers in the brackets are the standard deviation from the fitting routine.

\begin{tabular}{llll}
\hline Carbon atom type & vCF & RCF1 & RCF2 \\
\hline Graphitic, aromatics & $39.75(0.09)$ & $57.81(0.14)$ & $61.76(0.09)$ \\
$\beta$-carbons & $35.79(0.09)$ & $23.91(0.21)$ & $23.92(0.16)$ \\
Alcohols, phenols (C-OH) & $13.69(0.06)$ & $11.54(0.17)$ & $5.69(0.21)$ \\
Carbonyls (C=O, C=N) & $5.20(0.11)$ & $2.57(0.35)$ & $3.33(0.20)$ \\
Carboxylic (COOH, COOC) & $3.45(0.14)$ & $2.29(0.21)$ & $2.98(0.18)$ \\
$\pi \rightarrow \pi^{*}$ transition & $2.13(0.26)$ & $1.87(0.23)$ & $2.32(0.24)$ \\
O/C & $0.258(0.033)$ & $0.189(0.051)$ & $0.150(0.081)$ \\
\hline
\end{tabular}

Table 3. Contact angles of the three probing liquids on the virgin and recycled T800s carbon fibres and the surface energies of the carbon fibres calculated based on the contact angles. The numbers in the brackets are the standard deviation of the measurements.

\begin{tabular}{lllllll}
\hline & \multicolumn{2}{l}{ Contact angle $(\mathrm{SD})\left(^{\circ}\right)$} & \multicolumn{3}{l}{ Surface energy $\left(\mathrm{mJ} / \mathrm{m}^{2}\right)$} \\
\cline { 2 - 7 } & Bromonaphthalene & formamide & glycerol & total & ${\gamma^{\mathrm{d}}}^{\mathrm{d}}$ & $\gamma^{\mathrm{p}}$ \\
\hline vCF & $26.3(2.9)$ & $35.0(1.9)$ & $59.4(4.0)$ & 48.8 & 40.3 & 8.5 \\
RCF 1 & $27.2(1.2)$ & $30.4(1.2)$ & $53.4(2.6)$ & 49.5 & 40.1 & 9.4 \\
RCF 2 & $20.0(3.4)$ & $27.6(2.9)$ & $53.9(0.7)$ & 50.8 & 42.3 & 8.6 \\
\hline
\end{tabular}


Table 4. Microstructure parameters of the virgin and recycled T800s carbon fibres measured using XRD and Raman spectrometer.

\begin{tabular}{lllll}
\hline & Parameters & vCF & RCF1 & RCF2 \\
\hline XRD & $d_{002}(\mathrm{~nm})$ & 0.345 & 0.349 & 0.347 \\
& $L_{\mathrm{c}}(\mathrm{nm})$ & 1.87 & 2.12 & 2.06 \\
& $L_{\mathrm{a}}(\mathrm{nm})$ & 6.44 & 5.03 & 5.23 \\
\hline Raman & $G$ band position $\left(\mathrm{cm}^{-1}\right)$ & 1580 & 1599 & 1600 \\
& $G$ band width $\left(\mathrm{cm}^{-1}\right)$ & 102 & 89 & 100 \\
& $D$ band position $\left(\mathrm{cm}^{-1}\right)$ & 1350 & 1360 & 1362 \\
& $D$ band width $\left(\mathrm{cm}^{-1}\right)$ & 216 & 221 & 232 \\
& $I_{D} / I_{G}$ & 2.91 & 3.67 & 3.33 \\
\hline
\end{tabular}

Table 5. Tensile properties and interfacial shear strength (IFSS) of the virgin and recycled T800s carbon fibres with epoxy resin EF6305 and polypropylene. The number in the bracket is the standard deviation of the measurements.

\begin{tabular}{lccccc}
\hline & $\begin{array}{c}\text { Weibull mean } \\
\text { strength (MPa) }\end{array}$ & $\begin{array}{c}\text { Standard } \\
\text { deviation (MPa) }\end{array}$ & $\begin{array}{c}\text { Young's } \\
\text { modulus (GPa) }\end{array}$ & $\begin{array}{c}\text { IFSS with } \\
\text { epoxy (MPa) }\end{array}$ & $\begin{array}{c}\text { IFSS with PP } \\
\text { (MPa) }\end{array}$ \\
\hline vCF & 6965.6 & 2393.5 & $355.7(45.7)$ & $82.5(9.1)$ & $11.2(0.2)$ \\
RCF1 & 5876.3 & 1939.1 & $368.7(37.3)$ & $64.2(5.8)$ & $12.0(3.3)$ \\
RCF2 & 6795.0 & 2258.7 & $331.2(41.5)$ & $62.4(6.1)$ & $11.4(2.8)$ \\
\hline
\end{tabular}

